\title{
ERRATA
}

\section{ERRATUM TO: SERIES SOLUTION OF A TEN-PARAMETER SECOND-ORDER DIFFERENTIAL EQUATION WITH THREE REGULAR SINGULARITIES AND ONE IRREGULAR SINGULARITY}

\author{
A. D. Alhaidari*
}

DOI: $10.1134 / \mathrm{S} 0040577920100128$

Formula (36): the last term in the square brackets should be

$$
-\frac{U}{w^{2}}
$$

Formula (37c): the factor before the square brackets should be

$$
\frac{w^{2}}{x(1-x)(r-x)}
$$

Formula (38): the factor $(r-x)^{-1+c / 2}$ in the first line should be $(r-x)^{-1}$.

The original article can be found online at

https://doi.org/10.1134/S0040577920010031

${ }^{*}$ Saudi Center for Theoretical Physics, Jeddah, Saudi Arabia, e-mail: haidari@sctp.org.sa.

Translated from Teoreticheskaya i Matematicheskaya Fizika, Vol. 205, No. 1, p. 168, October, 2020. Received June 25, 2020. Revised June 25, 2020. Accepted June 25, 2020. 